2015-11-01

\title{
Investigating the Role of Shape on the Biological Impact of Gold Nanoparticles in Vitro
}

\author{
Furong Tian \\ furong.tian@tudublin.ie \\ Hugh Byrne \\ Technological University Dublin, hugh.byrne@tudublin.ie \\ Joao Conde \\ Massachusetts Institute of Technology
}

See next page for additional authors

Follow this and additional works at: https://arrow.tudublin.ie/biophonart

Part of the Biochemistry, Biophysics, and Structural Biology Commons, and the Biological and Chemical Physics Commons

\section{Recommended Citation}

Stoeger, T. et al. (2015) Investigating the Role of Shape on the Biological Impact of Gold Nanoparticles in Vitro", Nanomedicine, 10, 2643-2657 (2015). doi:10.2217/nnm.15.103

This Article is brought to you for free and open access by the DIT Biophotonics and Imaging at ARROW@TU Dublin. It has been accepted for inclusion in Articles by an authorized administrator of ARROW@TU Dublin. For more information, please contact arrow.admin@tudublin.ie, aisling.coyne@tudublin.ie,gerard.connolly@tudublin.ie. Funder: EU 


\section{Authors}

Furong Tian; Hugh Byrne; Joao Conde; Tobias Stoeger; Martin Clift; Alan Casey; Pablo del Pino; Beatriz

Pelaz; Barbara Rothen-Rutishauser;; Giovani Estrada; and Jesús de la Fuente 


\section{Investigating the role of shape on the biological impact of gold nanoparticles in vitro}

Furong Tian ${ }^{1,3^{*}}$, Martin JD Clift ${ }^{2 *}$, Alan Casey $^{3}$, Pablo del Pino ${ }^{4}$, Beatriz Pelaz ${ }^{5}$, João Conde $^{6}$, Hugh J. Byrne ${ }^{3}$, Barbara Rothen-Rutishauser ${ }^{2}$, Giovani Estrada ${ }^{7}$, Jesús M de la Fuente ${ }^{8}$ and Tobias Stoeger ${ }^{1 \dagger}$

(1) Comprehensive Pneumology Centre, Institute of Lung Biology and Disease, Helmholtz Zentrum München, Neuherberg, Germany.

(2) BioNanomaterials, Adolphe Merkle Institute, University of Fribourg, Switzerland.

(3) Nanolab Research Centre, FOCAS Research Institute, Dublin Institute of Technology, Camden Row, Dublin, Ireland.

(4) CIC biomaGUNE, San Sebastian, Spain

(5) Fachbereich Physik, Philipps Universität Marburg, Marburg, Germany

(6) Massachusetts Institute of Technology, Institute for Medical Engineering and Science, Harvard-MIT Division for Health Sciences and Technology, E25-449 Cambridge, Massachusetts, USA.

(7) Institute of Bioinformatics, Helmholtz Zentrum München, Neuherberg, Germany.

(8) Instituto de Ciencia de Materiales de Aragon CSIC-Universidad de Zaragoza, Spain

* Furong Tian and Martin JD Clift contributed equally.

\section{${ }^{\dagger}$ Corresponding author}

Tobias Stoeger, Comprehensive Pneumology Centre, Institute of Lung Biology and Disease, Helmholtz Zentrum München, Neuherberg, Germany.

Keywords: Gold nanoparticles, nanoparticle shape, biocompatibility, cell death, Cathepsin-B, CD95 (APO-1/Fas), Caspases, Reactive Oxygen Species, epithelial cells, nanotoxicology. 


\begin{abstract}
Aim: To investigate the influence of gold nanoparticle (GNP) geometry on the biochemical response of Calu-3 epithelial cells.

Materials and Methods: Spherical, triangular and hexagonal GNPs were used. The GNP-cell interaction was assessed via atomic absorption spectroscopy (AAS) and transmission electron microscopy (TEM). The biochemical impact of GNPs was determined over $72 \mathrm{hrs}$ at $[0.0001-1 \mathrm{mg} / \mathrm{mL}]$.
\end{abstract}

Results: At 1mg/mL, hexagonal GNPs reduced Calu-3 viability below $60 \%$, showed increased reactive oxygen species production and higher expression of pro-apoptotic markers. A cell mass burden of 1:2:12 as well as number of GNPs per cell (2:1:3) was observed for spherical:triangular:hexagonal GNPs.

\title{
Conclusion:
}

These findings do not suggest a direct shape-toxicity effect. However, do highlight the contribution of shape towards the GNP-cell interaction which impacts upon their intracellular number, mass and volume dose.

\section{Introduction}

Due to their plasmonic properties, gold nanoparticles (GNPs) have been proposed as advantageous nano-sized materials for use in the various diagnostic and therapeutic 
applications, such as cell imaging, targeted drug delivery, thermal ablation, phototherapy [17].. To date spherical GNPs have been proven as one of the most biocompatible NP models for biological-based applications [8-12]. Recently, it has been reported that the specific shape of GNPs can be exploited to advantageously tune these nanomaterials for any biomedical application of choice $[8,13]$. Examples of such alternatively shaped GNPs being produced include, amongst others, rods, triangles, hexagons, prisms, urchins, cubes and wires $[11,14]$. Triangular and hexagonal GNPs have been specifically reported as promising contrast agents for in vivo imaging applications in place of the commonly used spherical GNPs $[8,13,15]$. The reason for this is due to the shift of the optical resonance of these differently shaped GNPs to the near-infrared region of the spectrum, which allows for a greater potential to penetrate deeper inside tissues without photobleaching $[5,13,16]$.

Therefore, to envisage the use of these alternatively shaped GNPs within any potential medical applications their biocompatibility must be realised. In this regard increased attention has recently been focused towards their cellular interaction[17]. Although it is well known that specific physico-chemical characteristics (e.g. size, surface chemistry) of GNPs can indeed influence their cellular uptake and accumulation $[10,18]$, the ability for shape to play a significant role in their interaction of GNPs with mammalian cells in vitro is not fully understood. Many studies have undertaken investigations into how differently shaped NPs may interact with, or be internalised by mammalian cells [19], yet in order to fully comprehend the potential of alternatively shaped GNPs for biomedical applications, their biochemical impact must also be considered [20]. However, understanding as to how the manipulation of GNP shape relates to their biocompatibility is equivocal $[5,21,22]$. 
The aim of the present study, therefore, was to assess the biological impact of three differently shaped GNPs (spherical, triangular and hexagonal) with identical surface chemistry (applied with a common mass dose), upon a representative airway epithelial barrier (Calu-3) in vitro cell system. It is important to note that a pulmonary epithelial cell-line was chosen, since GNPs are successfully being developed for both systemic and local applications, i.e. for lung tumor delivery via inhalation[23]. Further to this, due to the fragility of the respiratory epithelium this area is considered particularly sensitive towards (nano)particle-cell interactions [24]. It was hypothesized that the shape of the GNPs, particularly due to their external dimensions, would play a role in the resultant biological impact of the GNPs in vitro. It is also noteworthy that since an observed change in biological impact might be related to NP surface chemistry rather than geometry[25], all GNPs were controlled for their surface functionalised with a carboxylated polyethylene glycol chain (SH-PEG-COOH) [26]. Furthermore, to ensure identical composition, all GNPs were collectively synthesized together prior to subsequent shape separation via electrophoresis [1].

\section{MATERIALS AND METHODS}

Chemicals and reagents. All chemicals and reagents were purchased from SigmaAldrich (Germany) unless otherwise stated.

Preparation of pristine GNPs. GNPs were prepared via reduction of chloroauric acid $\left(\mathrm{HAuCl}_{4}\right)$ using sodium thiosulfate as reducing agent as previously described in 
the synthesis of triangular gold nanoprisms $[8,13]$. Although nanoprisms are the main product of this synthesis, a small proportion (10-15\%) of spherical and hexagonal NPs can be obtained as a by-product. It is also important to note that due to the absence of any cationic detergent (e.g. CTAB - cetyltrimethylammonium bromide $\left.\mathrm{C}_{16} \mathrm{H}_{33} \mathrm{~N}\left(\mathrm{CH}_{3}\right)_{3} \mathrm{Br}\right)$, the synthesis method used represents a biocompatible alternative to using such cationic-based synthesis routes, and allows the surface of the GNPs to be readily functionalised with organic molecules.

Prior to use, all glassware was washed with aqua regia for at least 1 hour and rinsed thoroughly with Milli-Q water. A typical synthesis required $10 \mathrm{~mL}$ of $2 \mathrm{mM}$ chloroauric acid and $12 \mathrm{~mL}$ of $0.5 \mathrm{mM}$ sodium thiosulfate (reducing agent). Within the initial 5 minutes of the reaction, the colour of the solution changed from yellow (gold salt) to brownish, indicating the formation of GNPs. The reaction was subsequently stirred at room temperature for an additional 12 minutes prior to a second addition $(5 \mathrm{~mL})$ of reducing solution $(0.5 \mathrm{mM}$ sodium thiosulfate) and incubated for a further 78 minutes until complete. The formation of GNPs was confirmed via UV-Vis spectroscopy (Perkin Elmer Lambda 900 UV/VIS/NIR Spectrometer, USA).at an absorbance of 0.3 at wavelengths of $528 \mathrm{~nm}, 900 \mathrm{~nm}$ and $1100 \mathrm{~nm}$ respectively GNPs were stable in Milli-Q water for up to 12 months when stored at room temperature [13].

Surface functionalisation of GNPs with PEG. To promote their colloidal stability, GNPs were functionalised with hetero-bifunctional $\left(\mathrm{HS}-\mathrm{C}_{2} \mathrm{H}_{4}-\mathrm{CONH}-\mathrm{PEG}-\mathrm{O}-\right.$ $\mathrm{C}_{3} \mathrm{H}_{6}-\mathrm{COOH}$ (M.W. 5000 g/mol) (Rapp-Polymere, Tübingen, Germany) polyethylene glycol (PEG) chains as previously described [13]. Following surface 
functionalisation, $10 \mathrm{~mL}$ of GNPs was supplemented with $1 \mathrm{mg}$ of thiolated PEG, and the $\mathrm{pH}$ adjusted to 12 . Samples were then incubated overnight at room temperature. Following the incubation period, the free hetero-bi-functional spacer (HS-PEG$\mathrm{COOH}$ ) was removed by washing three times via centrifugation (11'200 rcf for 15 minutes). HS-PEG-COOH functionalised GNPs were then subsequently resuspended in Milli-Q water and lyophilised at a concentrated solution of $20 \mathrm{mg} / \mathrm{mL}$.

Shape separation of GNPs. As previously reported, the high colloidal stability of the NPs enabled separation of the GNPs functionalised with HS-PEG-COOH according to their electrophoretic mobility (i.e. via electrophoresis) [13]. Briefly, an aqueous solution of $0.8 \% \mathrm{w} / \mathrm{v}$ Agarose gel was prepared and immersed in Tris-borate-EDTA (TBE) buffer. The gel of $7 \times 7 \mathrm{~cm}$ and $1 \mathrm{~cm}$ thick was run on a horizontal electrophoresis system having an electrode spacing of $15 \mathrm{~cm}$ (Bio-Rad, Mini-Sub Cell GT System, USA). After electrophoresis at $200 \mathrm{~V}$, the shape separated GNPs were identified by their distinct colour bands (i.e. pink: spherical GNPs, black: triangular GNPs or grey: hexagonal GNPs) present on the electrophoresis gel. It is important to note that a $10 \%$ fraction of the hexagonal GNPs were observed to be of a triangular geometry. The concentration of each shaped GNP was $10 \mathrm{mg} / \mathrm{mL}$, as determined by inductively coupled plasma-mass spectrometry (ICP-MS) (Thermo Scientific, USA) [27]. The numbers of spherical, triangular and hexagonal GNPs per mL was determined to be $3.6 \pm 1.3 \times 10^{14}, 8.3 \pm 3.5 \times 10^{13}$ and $3.5 \pm 0.3 \times 10^{13}$ respectively (Table $1)$.

GNP Physico-chemical characterisation. The key physico-chemical characteristics of each differently shaped GNP are detailed in table 1. Each GNP type was suspended 
in Roswell Park Memorial Institute (RMPI) 1640 cell culture medium without any additional supplementation and analysed for their morphology, size and surface charge. To assess GNP morphology, a total of $10 \mu$ of GNP solution was pipetted onto a 300-mesh grid prior to evaluation by transmission electron microscopy (TEM) (Hitachi SU6600 instrument, Japan) (Figure 1). Additionally, TEM images were used to calculate the average dimensions of each GNP shape ( $\mathrm{n}=200$ GNPs counted)) (Table 1). To further assess the dimensions of each GNP, dynamic light scattering (DLS) was performed via a NanoZetasizer ZS analyser (Malvern Instruments, Worcestershire, UK). For size measurements, $100 \mu \mathrm{g} / \mathrm{mL}$ GNPs in RPMI 1640 medium were dispersed in DTS0012 cuvettes. The refractive index (RI) of 1.6 for GNPs was used [28]. Prior to analysis, viscosity measurements were performed on medium with the aid of a Viscometer SV-10 (A\&D Instruments Ltd., UK) at $25{ }^{\circ} \mathrm{C}$ and the recorded values used for all DLS size estimations. The samples were equilibrated at $25{ }^{\circ} \mathrm{C}$ for three minutes prior to each measurement. Additionally, the surface charge (i.e. zeta potential) of each GNP was also measured in supplemented RPMI 1640 medium (as stated above) by a NanoZetasizer ZS analyser (Malvern Instruments, Worcestershire, UK)[29]. For zeta potential measurements, DTS1060C clear disposable zeta cells were used and the measurements were performed at $5 \mathrm{~V}$. All characteristics were determined from three independent measurements $(n=3)$ at a concentration of $0.1 \mathrm{mg} / \mathrm{mL}$.

Cell culture. The human adenocarcinoma airway epithelial cell-line (Calu-3) was purchased from LGC Promochem (Wesel, Germany). This specific cell type was used as a model cell-line to study pulmonary exposure to GNPs. Cells were cultured in complete culture medium composed of RPMI 1640 with L-Glutamine (Invitrogen, 
Germany) supplemented with 10\% (v/v) Foetal Bovine Serum (Sigma Aldrich, Germany) and 1\% (v/v) $10000 \mathrm{U} / \mathrm{ml}$ Penicillin and $10000 \mathrm{U} / \mathrm{ml}$ Streptomycin (Invitrogen, Germany). Cells were maintained on flasks under standard culture conditions $\left(5 \% \mathrm{CO}_{2}, 95 \%\right.$ relative humidity and $\left.37{ }^{\circ} \mathrm{C}\right)$, and sub-cultured every 72 hours. Cell passage \# 7-10 at a seed density of $2 \times 10^{4} / \mathrm{cm}^{2}$ upon a seeding area of 0.8 $\mathrm{cm}^{2}$ was used for all experimentation, unless otherwise stated.

Estimation of internalised GNPs by Atomic Absorption Spectroscopy. Atomic Absorption Spectroscopy (AAS) was employed to quantify the total gold mass per dish using a SpectrAA200 (Varian, USA) atomic absorption spectrometer with direct comparison to a commercially purchased AAS gold standard (TraceCERT, Fluka) (Table 2). Cells were exposed, via the suspension method, to $1 \mathrm{mg} / \mathrm{mL}$ GNPs in 10 $\mathrm{mL}$ medium (10 mg NPs) in a $10 \mathrm{~cm}$ diameter petri-dish. After 72 hours exposure at $37{ }^{\circ} \mathrm{C}, 5 \% \mathrm{CO}_{2}$, the cell culture medium was removed and attached cells were thoroughly washed with PBS. To further remove GNPs that were loosely associated to the cell membrane, cells were washed with PBS and subsequently detached by trypsinization. Following this, cells were washed five times with PBS via centrifugation (10 minutes at $1400 \mathrm{rpm}$ ). Cells were then counted using a Z2 Coulter counter (Beckman Coulter, USA) and subsequently air-dried for 24 hours at room temperature. Following the incubation period, samples were dispersed in $8 \mathrm{~mL}$ water and then sonicated for 30 minutes at $135 \mathrm{~W}$ and room temperature to ensure a uniform distribution of GNPs in the sample prior to AAS analysis [31]. The total mass of associated (either internalised or tightly bound to the cell surface) gold per sample was determined by three independent measurements $(n=3)$ and presented as the average absorbance. In addition, the individual volume of single GNPs was observed 
by TEM, allowing for the further estimation of the total number of GNPs per dish (Table 2).

TEM. To determine the sub-cellular deposition of GNPs, conventional TEM was used. At a density of $5 \times 10^{5}$, Calu-3 cells were seeded in a $30 \mathrm{~mm}^{2}$ polystyrene dish for 24 hours at $37{ }^{\circ} \mathrm{C}, 5 \% \mathrm{CO}_{2}$. Please note that in accordance with the increased cell density, GNP concentration was also increased to serve the same NP per cell concentration. This was performed due to the inherent nature of TEM sample processing, in which cell number can be significantly reduced via the dehydration, washing and staining steps [30]. Cells were subsequently incubated with $0.1 \mathrm{mg} / \mathrm{mL}$ ( $3 \mathrm{~mL}$ volume) GNPs for 72 hours. It is further important to consider that the concentration used here corresponds to that used for AAS. Following the exposure period, cells were washed with three times with PBS and then fixed in $2 \%$ paraformaldehyde/2.5\% glutaraldehyde/0.15 $\mathrm{M}$ sodium phosphate at $\mathrm{pH} \quad 7.4$ overnight. Following the fixation period, samples were prepared for TEM as previously described by Brandenberger et al.[3] Ultrastructural analysis and photomicroscopy was performed with an EM400 TEM (Philips, The Netherlands). At least five independent fields of view from three individual samples were captured in order to provide a representative qualitative understanding of the interaction between the different shaped GNPs and the Calu-3 cells.

\section{Biocompatibility tests}

WST-1 Assay. At a density of $1 \times 10^{4}$ per well, cells were seeded (in a 6-well Petridish). After exposure to GNPs at 0.0001 to $1 \mathrm{mg} / \mathrm{mL}$ for 10 days, cells (which were grown in colonies) were stained violet in colour with Carbol Fuchsin Solution (VWR 
international, Ltd. England). Viable cells were subsequently normalised by plating efficiency controls [31]. Analysis was performed in triplicate from three independent experiments $(n=3)$. Data is presented as a percentage of cell viability compared to the negative control.

Assessment of Plasma Membrane Damage. The impact of GNP shape upon eliciting cell membrane damage was determined by the release of lactate dehydrogenase (LDH) from exposed cells, as quantified in cell culture supernatants by a CytoTox 96 cytotoxicity assay (Promega, Germany). At $1 \times 10^{4}$, Calu-3 cells were exposed to each differently shaped GNP at different concentrations for 72 hours. Triton $1 \%$ was used as positive control. Briefly, following manufacturer's guidelines, $50 \mu \mathrm{l} /$ well supernatant was collected, and then incubated with an equivalent volume of substrate solution for 30 minutes at room temperature in the dark. Following the incubation period, $50 \mu \mathrm{l} /$ well of stop solution was added. Each sample was filled by an Amicon Ultra-0.5 centrifugal filter device (Millipore, Germany) and spun at 6000 rpm for two minutes to remove the particles in suspension. The absorbance value of each filtrated sample was determined at a wavelength of $490 \mathrm{~nm}$ and $630 \mathrm{~nm}$ as reference via spectrophotometry. Since spherical GNPs have a spectrum of $528 \mathrm{~nm}$, the according concentration of spherical GNPs was used as a colorimeric control to remove the background absorbance. The triangular and hexagonal GNPs have a spectrum over 900nm and thus do not overlap with the wavelengths used within the LDH assay. Analysis was performed in triplicate from three independent experiments $(n=3)$. Data is presented as the percentage LDH release compared to the positive control (0.2\% Triton X100). 
Cathepsin-B expression. Cathepsin-B expression, was measured by a Cathepsin B expression Assay Kit (PK-CA577-K140, PromoKine, Germany) according to manufacturer's instructions. Briefly, Calu-3 cells were seeded at $1 \times 10^{4}$ and then exposed to each shape of GNPs at a concentration of $0.01,0.1$ and $1 \mathrm{mg} / \mathrm{mL}$ in a $96-$ well culture plate for 72 hours. Cells were then lysed in $50 \mu 1$ of chilled Cathepsin-B Cell Lysis buffer at $4{ }^{\circ} \mathrm{C}$ for 10 minutes. Subsequently, $50 \mu 1$ clear cell lysate was transferred to a 96-well plate and reacted with $50 \mu \mathrm{l}$ of Cathepsin B reaction buffer and $2 \mu \mathrm{l}$ of the $10 \mathrm{mM}$ Cathepsin B obtained from the kit (substrate Ac-RR-AFC (200 $\mu \mathrm{M}$ as final concentration)) and incubated for one hour at $37{ }^{\circ} \mathrm{C}$. Cathepsin $\mathrm{B}$ expression was then quantified by samples being measured in a fluorimeter (Spectra Max M3, Molecular Devices, USA) equipped with a $400 \mathrm{~nm}$ excitation filter and a $505 \mathrm{~nm}$ emission filter.

Furthermore, qualitative analysis was performed by laser scanning microscopy. Calu3 cells were seeded at a density of $1 \times 10^{4}$ cells $/ \mathrm{cm}^{2}$ and treated with $0.2 \mathrm{mg} / \mathrm{mL}$ GNPs in 8-well chamber slides for 72 hours. Cells were fixed with $-20{ }^{\circ} \mathrm{C}$ methanol for 10 minutes and with $-20^{\circ} \mathrm{C}$ acetone for 1 minute on microscope cover-slips. The coverslips were washed twice with PBS and then blocked with PBS containing 0.1\% BSA for 10 minutes at room temperature in the dark. Samples were incubated with Cathepsin-B (ab58802, Abcam, UK) in PBS containing 1\% bovine serum albumin (BSA) for 60 minutes, and were washed three times in PBS. Following this, samples were incubated with Fluorescein anti-rabbit (A10526, Invitrogen, Germany) as the secondary antibody at a 1:40 dilution in PBS containing 1\% BSA for 30 minutes at room temperature. Samples were subsequently washed three times in PBS. Samples were then stained for both the cytoskeleton (F-actin labelled with Texas Red® 
Phalloidin (T7471)) and the nuclear region (labelled with 4',6-diamidino-2phenylindole dye (DAPI)). ProLong Gold Antifade reagent (Invitrogen, Germany) was added onto the cover-slips before they were carefully inverted onto glass microscope slides. After the incubation period, samples were washed twice and images obtained by laser scanning microscopy (Carl Zeiss 510, Germany at a 63x magnification) as previously described [27]. At least five independent fields of view from three individual samples were captured in order to provide a representative qualitative understanding of Cathepsin-B expression in Calu-3 epithelial cells following GNP exposure.

Reactive oxygen species (ROS) production. The ability for each type of GNP to generate ROS was determined by the DCFH-DA assay. It is important to note that DCFH-DA diffuses through the cell membrane readily and is hydrolysed by intracellular esterases to non-fluorescent DCF deacetylated, which is then rapidly oxidised to highly fluorescent DCF in the presence of ROS. The DCF fluorescence intensity is proportional to the amount of ROS formed inside the cell [26]. Further to this, when assessing the cellular associated ROS generation, the mitochondrial distribution of the ROS formation was assessed via the concomitant use of the MitoTracker Red CMXRos dye.

The ability for GNPs to elucidate ROS formation within cells was determined. Initially, Calu-3 cells were seeded at a density of $1 \times 10^{4}$ and treated with $0.2 \mathrm{mg} / \mathrm{mL}$ GNPs in an eight well chamber slide for 72 hours at $37{ }^{\circ} \mathrm{C}, 5 \% \mathrm{CO}_{2}$. Cells were loaded with the fluorescent indicator at a final concentration of $300 \mathrm{nM}$ with MitoTracker Red CMXRos dye (Catalogue number: M-7512; excitation/emission: 
$579 / 599 \mathrm{~nm}$, Invitrogen,) $10 \mathrm{mM}$ DCFH-DA dye and $0.2 \mu \mathrm{g} / \mathrm{mL}$ DAPI for 30 minutes at $37{ }^{\circ} \mathrm{C}, 5 \% \mathrm{CO}_{2}$ in the dark. After the incubation period, samples were washed twice and images obtained by laser scanning microscopy (Carl Zeiss 510, Germany at a 63x magnification) as previously described [32]. At least five independent fields of view from three individual samples were captured in order to provide a representative qualitative understanding of the ROS production in Calu-3 cells following GNP exposure.

Apoptosis Immunostaining. Calu-3 cells were seeded at a density of $1 \times 10^{4}$ cells $/ \mathrm{cm}^{2}$ and treated with $0.2 \mathrm{mg} / \mathrm{mL}$ GNPs in 8 -well chamber slides for 72 hours. Cells were fixed with $-20{ }^{\circ} \mathrm{C}$ methanol for 10 minutes and with $-20{ }^{\circ} \mathrm{C}$ acetone for 1 minute on microscope cover-slips. The cover-slips were washed twice with PBS and then blocked with PBS containing $0.1 \%$ BSA for 10 minutes at room temperature in the dark. Samples were incubated with anti-Caspase-8 rabbit (IMG-5704, Imgenex, USA) in PBS containing $1 \%$ bovine serum albumin (BSA) for 60 minutes, and then washed three times in PBS. Following this, samples were incubated with Alexa 546 antirabbit (A11035, Invitrogen, Germany) as the secondary antibody and a green phalloidin probe (A12379, Invitrogen, Germany) (to denote the cell F-actincytoskeleton) at a 1:40 dilution in PBS containing 1\% BSA for 30 minutes. Samples were subsequently washed three times in PBS. After staining the nuclear region with 4',6-diamidino-2-phenylindole dye (DAPI), one drop of ProLong Gold Antifade reagent (Invitrogen, Germany) was added onto the cover-slips before they were carefully inverted onto glass microscope slides. Samples were then imaged by laser scanning microscopy (Carl Zeiss 510, Germany, at a 63x magnification). With each method, four images per sample were captured to gain a representative understanding 
of the onset of apoptosis in Calu-3 epithelial cells following GNP exposure. Subsequently image analysis was performed (i.e. quantification of fluorescent density) with ImageJ (a Java-based software freely available at NIH, version $1.45 \mathrm{~s}$ ), according to the procedure described in [26].

Fas-Receptor and Caspase protein expression. At $5 \times 10^{5}$ Calu- 3 cells were seeded in a $30 \mathrm{~mm}^{2}$ polystyrene dish and exposure with different concentrations of GNPs from $0.02,0.1,0.2,0.5$ and $1 \mathrm{mg} / \mathrm{mL}$ for 72 hours. Protein extract of Calu-3 cells was boiled in sample buffer for 3 minutes and loaded onto 12\% SDS-polyacrylamide gels. Details of the Western immunoblotting procedure are described in the previous work of Tian et al. [32]. Total protein of each sample was then quantified using a protein quantification reagent from Bio-Rad (Bio-Rad Protein Assay Dye Reagent (\#5000006), Munich, Germany) and the same amount of protein was loaded onto the gel as described elsewhere [33]. The antibodies used for this experiment were as follows: rabbit anti-Fas (X-20, sc-1024 Santa Cruz Biotechnology, USA), rabbit anti- active Caspase-3 that recognizes the cleaved CASP3 fragment, AS 171-175 of P42574 (D175, mAb clone 9H19L2, Catalog number 700182, Invitrogen, Germany), rabbit anti-active Caspase-9, that recognizes the cleaved CASP9 fragment adjacent to Asp353 (ab52298 Abcam, UK; 1:1000 dilution), and anti-rabbit IgG horseradish peroxidase (Amersham-Pharmacia Biotech, UK; 50000:1 dilution). The Western blot was visualised using a chemiluminescence kit (ECL, Amersham-Pharmacia Biotech) and Western blots were transferred to Bio-RAD Imaging, USA. A densitometric analysis was performed using ImageJ (version 1.45s) and protein expressions were normalised to the density of $1 \mathrm{mg} / \mathrm{mL}$ hexagonal GNPs respectively (100\%) Analysis was performed in triplicates and from three independent experiments $(n=3)$. 
Statistical analysis. All data is presented as the mean \pm standard deviation (SD). Significant differences between two groups were evaluated by a Student's $t$-test, or between multiple groups via a two-way ANOVA. Regression analysis was performed, as well as Tukey's multiple comparison post-hoc tests to identify the source of variance. Statistical analysis was performed using GraphPad Prism 5.0 (GraphPad Software, USA). The alpha value was set to 0.05 .

\section{RESULTS}

GNP physico-chemical characteristics. The main physico-chemical properties of each shape, including diameter, volume, thickness, absorbance peak, surface modification and charge are listed in table 1. Briefly, TEM and SEM analysis revealed spherical GNPs to have an average diameter of $30 \mathrm{~nm}$ (Fig. 1A, A'). Both the triangular and hexagonal GNPs were found to be $\sim 9 \mathrm{~nm}$ thick [8], with a respective average side length of triangles and longest diagonal for hexagon being 120 $\mathrm{nm}$ and $150 \mathrm{~nm}$ (Fig. 1B, B' and 1C, C'). All three GNP types were found to exhibit a 
negative zeta potential in cell culture medium (-17.7 to $-16.3 \mathrm{mV}$ ) (Table 1). Despite the same surface chemistry, the different GNPs exhibited an altering surface area $\left(\mathrm{nm}^{2}\right)$ (2827.4 (spherical), 12470.4 (triangular), 38971.1 (hexagonal)) and volume $\left(\mathrm{nm}^{3}\right)$ (14137 (spherical), 56118 (triangular), 131528 (hexagonal)) per GNP.

Association of GNPs with Calu-3 cells. Following numerous washing steps, as well as trypsinization, all AAS analysis was based on the assumption that the measured quantity of gold can be considered as GNPs either internalised or tightly attach to the surface of cells. No significant difference was observed between the total mass of triangular and spherical GNPs measured per dish (Table 2). The total mass measured per dish for the hexagonal GNPs, however, exceeded both the spherical and triangular GNPs by a factor of two and five respectively (Table 2). Adjusting for the cell numbers per plate indicates that $0.22,0.42$ and $2.65 \mathrm{ng}$ gold could be associated per cell for spherical, triangular and hexagonal GNPs. To further estimate the number of GNPs per cell, the number of GNPs per dish was estimated by the specific volume of each different shaped GNP (Table 2). From the calculated particle volume, it was subsequently possible to determine the number of GNPs per cell (also considering the cell density per dish) to be triangle $<$ spherical $<$ hexagonal. This finding was important in considering the role played by each GNP type in the subsequent biochemical effects observed $(p<0.01)$ (Table 2). Considering further the size of the different GNPs, the respective volumes occupied by this GNP number per cell of spherical, triangle and hexagonal GNPs proved to be 1:2:11 (in detail: $1.1 \times 10^{5}, 2.0 \times 10^{5}$ and $1.2 \mathrm{E} \times 10^{6} \mathrm{~nm}^{3} /$ cell). 
Sub-cellular distribution of GNPs. After 72 hours suspension exposure to 0.1 $\mathrm{mg} / \mathrm{mL}$, spherical GNPs were found to be both freely-distributed in the cytoplasm, as well as located in membrane-bound compartments of Calu-3 cells (Fig. 2). The image in Fig. 2A' shows a vesicle, confirmed via distinctively contrast stained membrane contours, containing spherical GNPs. Similar findings were also observed for the triangular GNPs (Fig. 2B). The varying intracellular localisation of the two different shaped GNPs could suggest a number of different uptake routes occurring simultaneously by the Calu-3 cells, or that the GNPs are able to escape from the vesicles, during the intracellular trafficking cascade, into the cytosol. However, at this sample point, hexagonal GNPs were only found to be present within membranebound compartments inside Calu-3 cells (Fig. 2C). It is also noticeable that triangular shaped GNPs are within this vesicle (Fig. 2C). This is due to the fraction (10\%) of triangular GNPs from the shape separation technique used for the hexagonal GNPs.

Shape-dependent impact on cell viability and cytotoxicity. Triangular GNPs exhibited a reduced survival rate compared to spherical GNPs after 72 hours following exposure up to $1 \mathrm{mg} / \mathrm{mL}$ (91\% triangular vs. $99 \%$ spherical). Despite these differences, no significant $(p>0.05)$ changes in cell viability were observed for either GNP type compared to the negative control at all concentrations tested (Fig. 3A). In contrast, a significant $(p<0.05)$ loss, compared to negative control levels, in Calu-3 cell viability was found following exposure to hexagonal GNPs (57\% viable) for 72 hours at $1 \mathrm{mg} / \mathrm{mL}$ (Fig. 3A). Noticeably, Calu-3 cells remained viable for all GNP shapes and concentrations up to $0.1 \mathrm{mg} / \mathrm{mL}$ after 72 hours (Fig. 3A). Further to the findings at $1 \mathrm{mg} / \mathrm{mL}$, the loss in cell viability observed after hexagonal GNP exposure 
was found to be significantly different $(p<0.01)$ to the status of the Calu-3 cells after exposure to both spherical and triangular GNPs (Fig. 3A).

No significant $(p>0.05)$ LDH release was observed for either the spherical or triangular GNPs after exposure for 72 hours up to a test concentration of $1 \mathrm{mg} / \mathrm{mL}$ (Fig. 3B). At the same particle concentration, hexagonal GNPs showed a significant $(p<0.05) \mathrm{LDH}$ release, exceeding $10 \%$ over control levels, as well as to both the spherical and triangular GNP at all concentrations tested (Fig. 3B).

Cathepsin-B expression. Spherical and triangular shaped GNPs showed limited changes to the presumed punctuated lysosomal Cathepsin-B expression compared to the negative control, as determined via laser scanning microscopy (Fig. 4A-C). Treatment with hexagonal GNPs caused a significant alteration to cell morphology, with deformed and disintegrated F-actin cytoskeleton indicating the progression of apoptotic degeneration (Fig. 4C), as compared with the negative control (Fig. 4A). Strong Cathepsin-B protein expression, evident by bright fluorescence signals in perinuclear granules, was also observed for hexagonal but not spherical or triangular GNP treated cells (Fig. 4D). In support of the microscopy approach, subsequent quantitative analysis of Cathepsin-B activity showed that the protease activity in cell extracts of hexagonal-treated cells exceeds that of the negative control and triangular GNPs in a concentration-dependent manner ( $p<0.001)$ (Fig. 4E).

ROS production. In cells dosed with $0.2 \mathrm{mg} / \mathrm{mL}$ hexagonal GNPs a strong DCFHDA derived DCF-fluorescence signal indicated substantial ROS activity in the vicinity of the MitoTracker (TMRM) signal, a mitochondrial membrane potential sensitive 
dye (Fig. 5C, D). No sign for ROS formation was observed for triangular (Fig. 5A, B) as well as spherical particles (not shown). The overall diffuse DCF signal and the weak overlap with the localization of the TMRM fluorescence indicates that the hexagonal GNPs caused intracellular ROS formation is not significantly associated to the mitochondria, and therefore might not be caused by mitochondrial destabilization.

Shape-dependent stimulation of CD95 (APO-1/Fas) receptor and Caspases. No Caspase- 8 expression was found in Calu-3 cells treated with spherical (data not shown) or triangular shaped GNPs (Fig. 6B). In contrast a strong cytoplasmatic expression was detected in cells following exposure to hexagonal GNPs after 72 hours at $0.2 \mathrm{mg} / \mathrm{mL}$ (Fig. 6D). Since Caspase- 8 is an initiator Caspase activated by the extrinsic death receptor pathway, such as the Fas receptor (CD95), which in turn activates effector caspases like caspase 3 either directly or via the mitochondria mediated Caspase- 9 apoptosome, the expression of Caspase-3 and -9, as well as Fas in Calu-3 cells were further investigated by immunoblotting. Expression of Fas, activated Caspase-3 (19kDa form) and activated Caspase-9 (21 kDa form) was significantly higher for the hexagonal GNPs at $0.2,0.5$ and $1 \mathrm{mg} / \mathrm{mL}$ compared to both triangular and spherical GNPs (Fig. 7). The dose response for Fas and Caspases3 expression levels showed a sigmoidal curve suggesting the onset of apoptosis in Calu-3 epithelial cells requires a minimal dose of $0.1-0.2 \mathrm{mg} / \mathrm{mL}$ of hexagonal GNPs for 72 hours (Fig. 7). Importantly, no significant expression changes $(p>0.05)$ were observed for spherical and triangular GNPs, neither for the Fas death receptor nor for the activation indicating caspase forms at any of the concentrations studied (Fig. 7). 


\section{DISCUSSION}

It is widely accepted that both geometric properties and surface design can significantly alter the interaction of NPs with cells, cellular membranes, as well as influence their intracellular localisation and distribution. Nonetheless, prediction of biocompatibility based on NP shape and dimensions is extremely challenging [34-36]. Despite this, novel NPs are constantly being created in a wide range of shapes (e.g. hexagons, triangles, urchins, roses, needles) $[8,13]$. Currently though, it is unclear 
how the specific tuning of NP shape can be achieved in order to serve as precise (biomedical) tools whilst eliciting limited impact upon cellular homeostasis. The aim of the present study therefore, was to study a panel of three differently shaped GNPs with identical surface chemistry and determine their impact upon the biocompatibility to the airway epithelia using the Calu-3 cell-line as a model.

In summary, the shape-related GNP biocompatibility investigated within the current study followed the sequence of spherical $>$ triangular $>>$ hexagonal. The findings of the present study clearly show that both spherical and triangular GNPs, in contrast to hexagonal GNPs, elicited only limited, if not negligible cytotoxicity, whilst hexagonal GNPs, at least at doses exceeding $0.1 \mathrm{mg} / \mathrm{mL}$, significantly affected cell viability. It is important to note however, that the concentration $(1 \mathrm{mg} / \mathrm{mL})$ causing a severe cytotoxic effect upon Calu-3 cells following hexagonal GNP exposure may be considered as a factitious high dose situation [37]. This is evident as shown in figure $3 \mathrm{~A}$ where the viability of the Calu-3 epithelial cells treated with more than $0.1 \mathrm{mg} / \mathrm{mL}$ of hexagonal GNPs is dropping to $80 \%$ compared to controls, while spherical and triangular GNPs show no effect, indicating doses over $0.1 \mathrm{mg} / \mathrm{mL}$ represent a cytotoxic concentration. Also at doses from $0.2 \mathrm{mg} / \mathrm{mL}$, for hexagonal GNPs, the Factin cytoskeleton was found deformed, caspases activity (indicates the strong activation of both intrinsic and extrinsic apoptotic pathways) increased and the expression of lysosomal enzyme Cathepsin-B heightened. The onset of apoptotic cell death within Calu-3 epithelial cells over the 72 hour exposure period to hexagonal GNPs can further be associated with the significant increase in non-mitochondrial ROS production since the induction of cell death can be elucidated by an increase in ROS, and are in support of the findings of a recent study by Hutter et al. [6]. 
Furthermore, these findings support previous research that has shown spherical, isotropic GNPs larger than $5 \mathrm{~nm}$ to cause limited influence upon cell viability [38], while less is known for anisotropic GNPs such as triangular or hexagonal shapes [39].

When focussing on these findings it might be considered surprising that at an equal applied mass dose, sharp angular shaped triangular gold platelets are less cytotoxic than hexagonal objects of comparison. In this context, a related study identified triangular silver nanoplates to be more toxic to hepatocellular carcinoma cells than silver nanospheres[40]. However in the present study, the biocompatibility of the known reactive vertices of the triangular GNPs revealed to be indistinguishable from spherical GNPs[8]. It is possible, in this regard, that the adverse biological impact noted may be influenced by a multitude of factors such as, aspect ratio, particle size and particle surface area [41,42]. Although such an effect could also suggest that a threshold exists as regards the specific surface geometry (i.e. number of 'vertices') of GNPs and their resultant biological impact. For example, when based upon the cytotoxicity data presented in the currently manuscript, it could be hypothesised that the heightened number of vertices are directly related to the increase in cell membrane damage (LDH release). This hypothesis can be attributed to the fact that NPs with an increased number of vertices can elicit a heightened (surface) reactivity which, when considered in regards to their interaction with cellular membranes could elicit a negative biological impact[40]. Further research is necessary however, to associate this hypothesis with the vertices of the hexagonal GNPs used in this study.

Nonetheless, why hexagonally-shaped GNPs elicit a decrease in epithelial cell viability is not abundantly apparent, despite the clear differences in biochemical 
response between the three GNP shapes. Thus, a number of additional hypotheses can also be considered. One possibility is that the individual hexagonal GNPs are heavier than the triangular GNPs. Furthermore, since the hexagonal GNPs encompass a greater number of vertices (6) than the triangular (3), the number of protein binding sites is increased; proposing a greater possibility of a potential immunomodulatory impact upon cells. If however, as suggested above, geometry was considered a secondary issue for cytotoxicity, and the NP-cell interaction was analysed in terms of NP mass, as well as number and volume, a different picture arises. This approach has most notably been observed by Ferin et al., in one of the first studies to report the biological impact of nano-sized materials, [43]. Even though the numbers of GNPs 'associated' with the cells seem comparable for spherical, triangular and hexagonal GNPs and differ only by about two fold (2.3 / $1 / 2.7)$, the ratio of the corresponding GNP mass matches well with their previously described order of toxicity. Accordingly, the cell associated hexagonal GNP mass occupied a 12 times higher volume as compared to spherical, and a six times higher volume as compared to triangular GNPs. A similar estimate of course applies for the respective particle surface area, which has been established as the most appropriate dose-metric for comparing the effects of NPs of different sizes[37,44,45]. In this regard, the subcellular deposition of GNPs shows some interesting differences between the shapes. It is known that GNPs are often confined to endosomes and similar compartments when cells undergo endocytosis [46]. As further denoted in table 2, there were $8.06 \mathrm{E}^{+5}$ spherical GNPs and $5 \mathrm{E}^{+5}$ triangular GNPs per and $9.4 \mathrm{E}^{+5}$ hexagonal GNPs per cell after $72 \mathrm{~h}$ exposure. Hexagonal GNPs were only found to be located in vesicles, while spherical GNPs and triangular GNPs were found both inside and outside of membrane-bound compartments inside Calu-3 epithelial cells; a possible reasoning 
behind the increased Cathepsin B expression following exposure to the hexagonal GNPs. Thus, the mode of interaction (i.e. cellular uptake mechanism) could play a pivotal role in how the cells internalise the GNPs and therefore contributing to the biocompatibility of GNPs.

In addition to the specific uptake mechanisms at play, the precise physical manner in which different shaped nanomaterials interact (or associate) with cells has been of increased interest recently. Most notably, the concept of 'angle of attack' has been considered [47]. In this regard, it is conceived that the NPs interact with the cell surface and the total parallel component of the kinetic energy produced contributes to a cutting wear [48]. Therefore, due to the small, flat surface of the hexagonal GNPs, it can be assumed that the hexagonal GNPs could engage in a small angle of attack resulting in a greater mass internalisation of hexagonal GNPs within the Calu-3 cells compared to the spherical and triangular GNPs $(0.53 \pm 0.05 \mathrm{mg}$ vs. $0.11 \pm 0.04 \mathrm{mg}$ (spheres) and 0.19 $\pm 0.08 \mathrm{mg}$ (triangular)). However, such assumptions are based upon modelling, or upon larger particle sizes. Alternatively however, strong consideration for the physical parameters acting upon the cellular interaction of the different shaped GNPs should be given towards the increased mass internalised by the Calu-3 cells, and the potential for a heightened sedimentation rate of the heavier hexagons compared to both the spheres and triangles[49]. Although further research is necessary to deduce between these aspects, the difference in total mass of GNPs per cell) is subsequently postulated as contributing to the differences in the biochemical responses observed between the different GNP shapes when considered with their surface area. As, although hexagonal GNPs show a three times greater internalised mass per cell compared to the triangular GNPs, they are similar to that of the spherical 
GNPs. However, since the internalized particle surface area of hexagonal GNPs exceeds that of the spheres and triangles by a factor of 10 , this increase in the cell associated particle dose likely explains the observed increases in cellular stress and cytotoxicity. Thus it is strongly advised that NP biocompatibility and toxicological studies, in addition to the 'administered mass', consider the 'cell delivered' dose metric, as this is suggested as being highly relevant for insoluble materials.

\section{CONCLUSION}

In conclusion, it is not only the geometry of GNPs directly driving their biocompatibility with Calu-3 epithelial cells, but when exposed at the same mass dose, the intracellular number, mass and volume of GNPs resultant of their specific interaction and internalisation that contributes towards the observed adverse cellular response. Therefore, it is these, combined characteristics that are crucial determinants 
that require particular consideration in the development of safe, biocompatible nanomaterials for biomedical applications.

\section{SUMMARY POINTS}

- The present study shows, via a systematic study, the impact of Au NP geometry upon lung cell homeostasis in vitro.

- At sub-lethal concentrations, the adverse biological impact (increase of reactive oxygen species, apopototic pathways and lysosomal burst) of alternative Au NP geometry showed hexagons>triangles>spheres. 
- The impact of differently shaped Au NPs is not specific to the NP shape, however is due to a convoluted paradigm combining the physico-chemical characteristics of surface area, volume and mass. Together with NP concentration and number, these variables were all considered to significantly influence the interaction of Au NPs with altered geometry with lung epithelial cells in vitro. A use of the 'delivered to cell' dose metric might be toxicologically more relevant than the 'administered mass' itself.

- Au NPs varying in their geometry must be individually considered for their hazard potential prior to their proposed advantageous use within nanomedical applications.

\section{FINANCIAL DISCLOSURE/ACKNLOWEDGEMENTS}

This study was partially financed by the European Commission via ERANanoScience, project "NanoTruck" awarded to JMF and FT. FT and JC are currently Marie Curie Fellows. AC and HJB acknowledge the support of Science Foundation Ireland 11/PI/1108. JMF thanks MAT2011-26851-CO2-01 project of the Spanish Ministry of Science and Innovation and Fondo Social Europeo (FSE; Gobierno de 
Aragón), for partially financing this research. BP acknowledges to the Alexander von Humboldt Foundation for her fellowship. MJDC and BRR acknowledge the funding received from the European Respiratory Society (Fellowship LTRF-MC1572-2010 to MJDC) and the Adolphe Merkle Foundation.

\section{ETHICAL CONDUCT OF RESEARCH}

The authors declare no conflict of interest. The authors are entirely responsible for the writing of the manuscript and the data contained within it. All authors have adopted the EU ethical guidelines for scientific research at all times during this project.

\section{FIGURES}



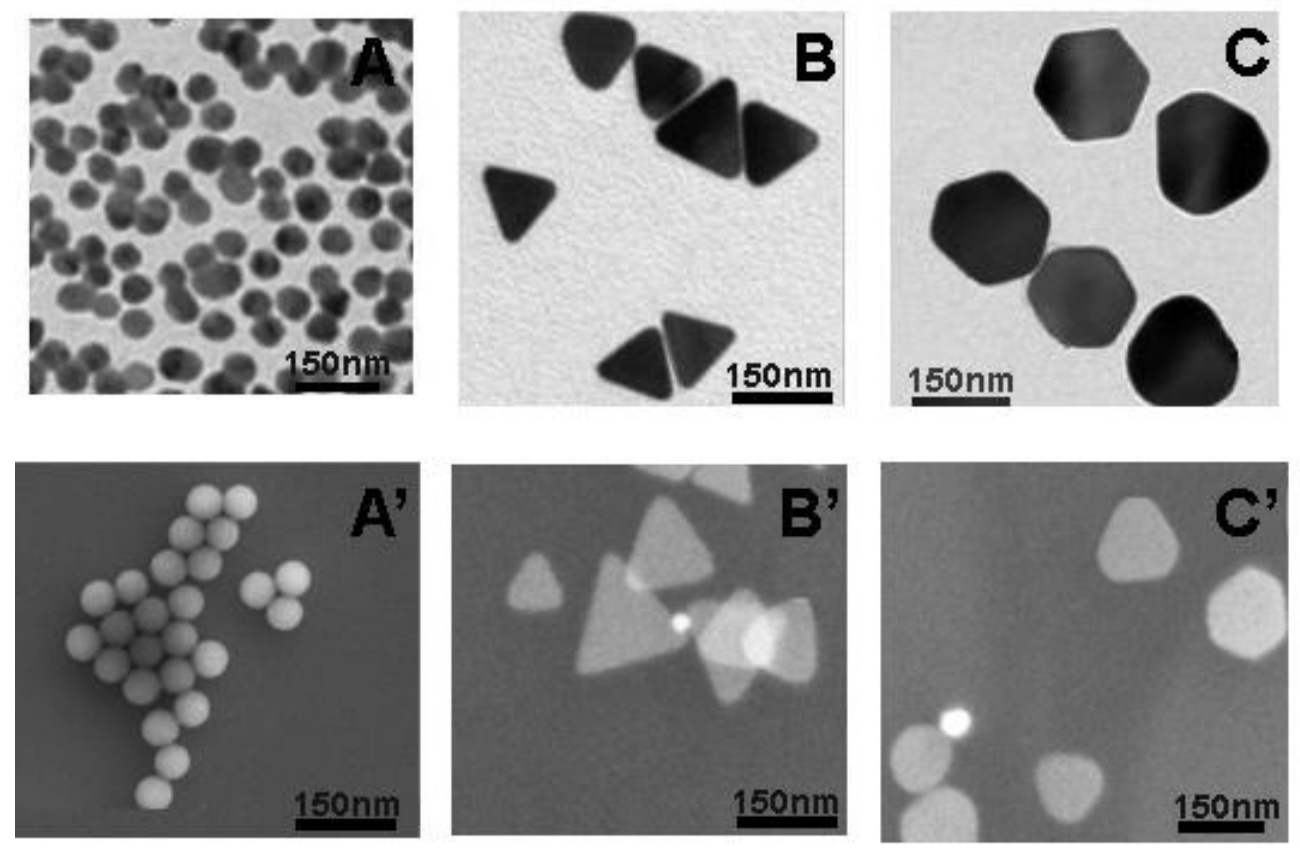

Figure 1. Morphology of the different shaped GNPs. Images show the morphological aspects of (A, $\left.\mathbf{A}^{\prime}\right)$ spherical, (B, B') triangular and (C, $\left.\mathbf{C}^{\prime}\right)$ hexagonal shaped GNPs as used in the present study. (A-C) show Transmission electron microscopy images. (A'C') show scanning electron microscopy images. Scale bar represents $150 \mathrm{~nm}$. Please refer to table 1 for the key physico-chemical characteristics of all three different GNP shapes. 

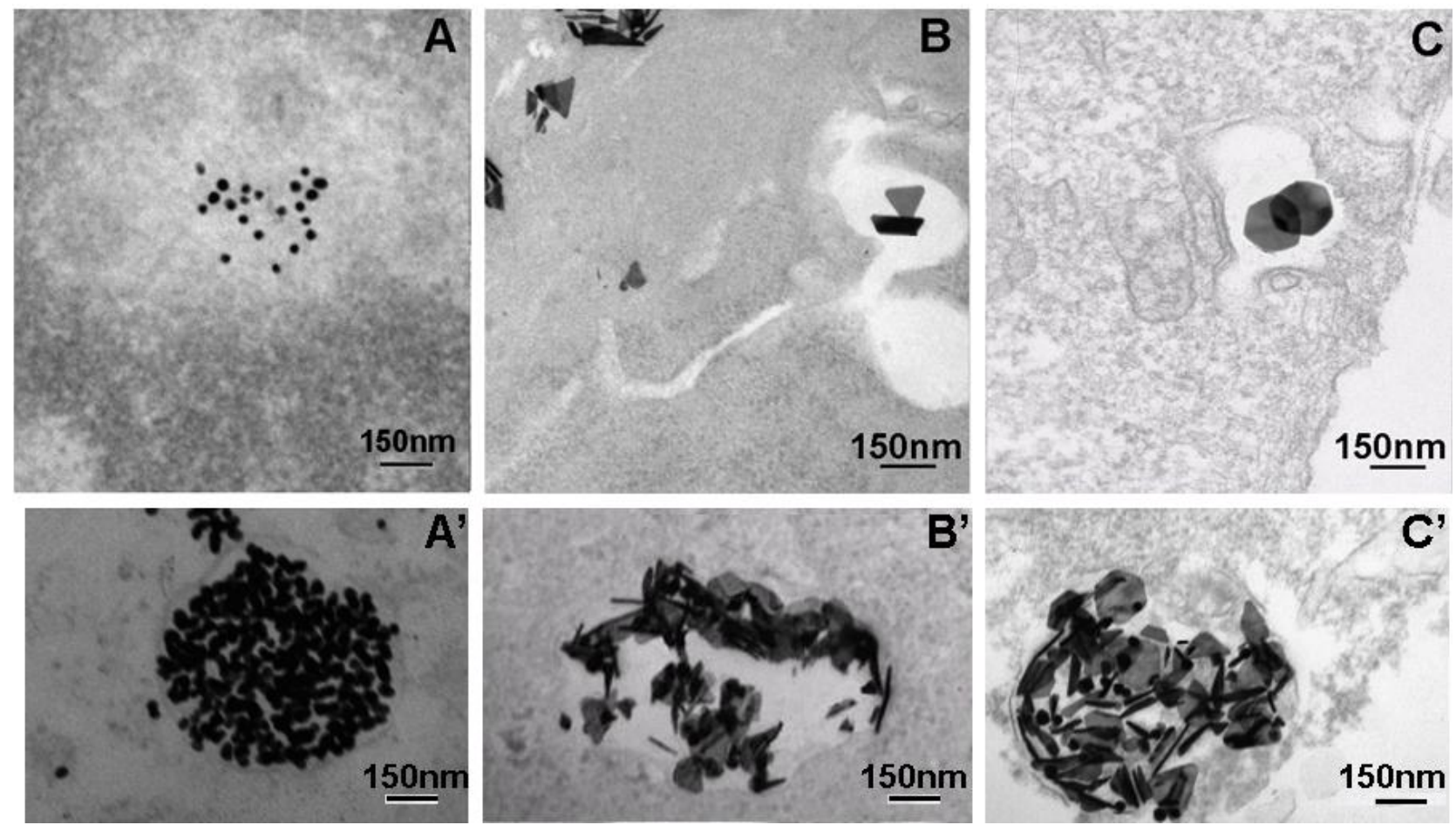

Figure 2. Transmission electron microscopy images of the sub-cellular localisation of the different shaped gold nanoparticles (GNPs) in Calu-3 epithelial cells after 72 hours exposure at $[1 \mathrm{mg} / \mathrm{mL}]$ under suspension culture conditions $\left(37^{\circ} \mathrm{C}, 5 \% \mathrm{CO}_{2}\right)$. In image (A), spherical GNPs are shown to be free within the cytoplasm of the cells, whilst (A') shows spherical GNPs to be localised within a membrane-bound compartment. (B) Triangular GNPs were found to reside with a membrane bound compartments, as further highlighted by the magnified image (B'). Image B also shows the triangular GNPs to be free within the cytoplasm of the cell at this time. Images $\mathbf{C}$ and $\mathbf{C}^{\prime}$ indicate that the intracellular localisation of the hexagonal GNPs is within vesicular compartments of the Calu-3 cells. For each replication $(n=3)$, a total of 5 fields of interest were observed in order to capture a representative image of each shaped GNP-cell interaction. Scale bar equals 150nm. 

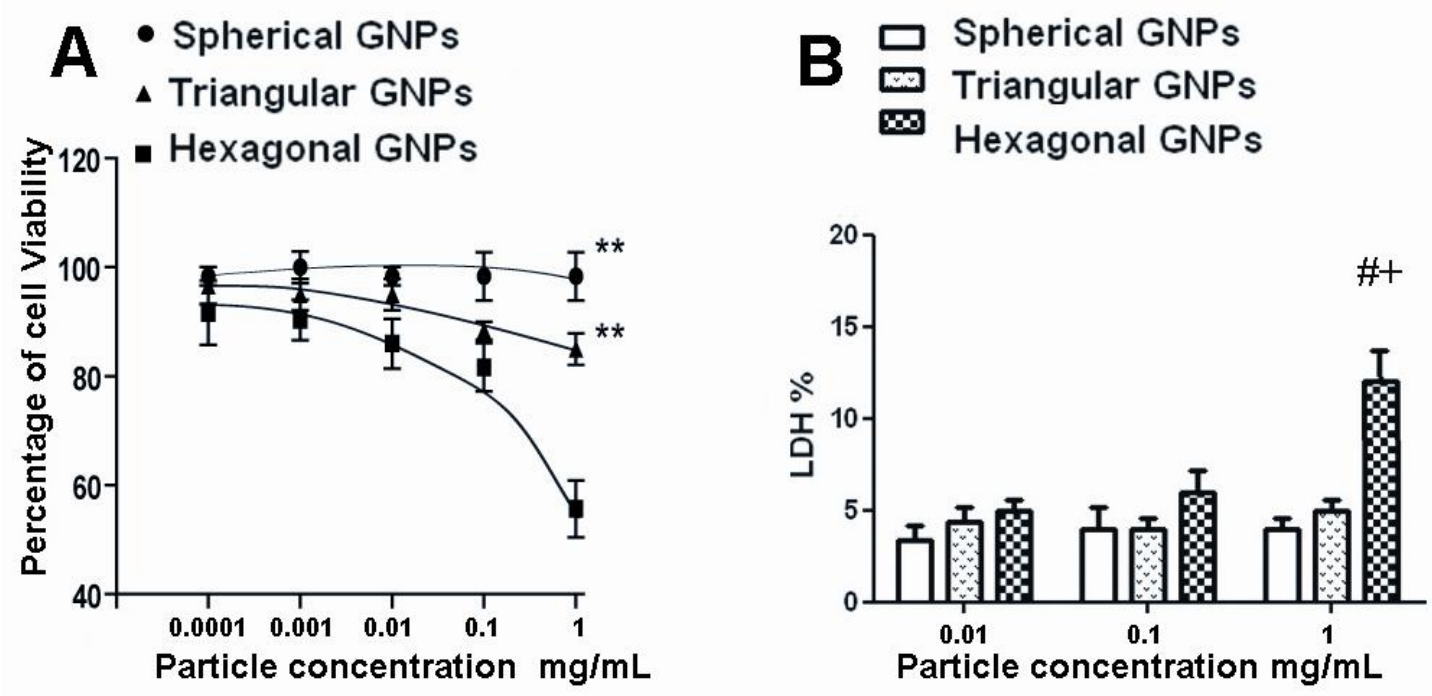

Figure 3. Shape-dependent cytotoxicity upon Calu-3 epithelial cells. (A) Shows the percentage of cell viability (WST-1 assay) and (B) the cytotoxicity indicated by lactate dehydrogenase (LDH) release after 72 hours exposure to GNPs. Cell viability (WST-1) and membrane permeability (LDH release) were analysed with concentrations ranging from [0.00001 to $1 \mathrm{mg} / \mathrm{mL}$ ] for 72 hours under suspension culture conditions $\left(37^{\circ} \mathrm{C}, 5 \% \mathrm{CO}_{2}\right)$. The effect of the GNPs on cell viability had the following sequence: spheres $>$ triangular $>>$ hexagonal GNPs $(* * p<0.01$ compared to hexagonal groups). A similar sequence was also noted for the ability for GNPs to cause cell membrane disruption related to $\mathrm{LDH}$ release (\# $p<0.05$; compared to spherical groups, $+p<0.05$; compared to and triangular groups). The LDH percentage has been normalized against the positive control (0.2\% Triton X100). Data shown is the mean \pm standard error of the mean $(\mathrm{SEM})(n=3)$. 

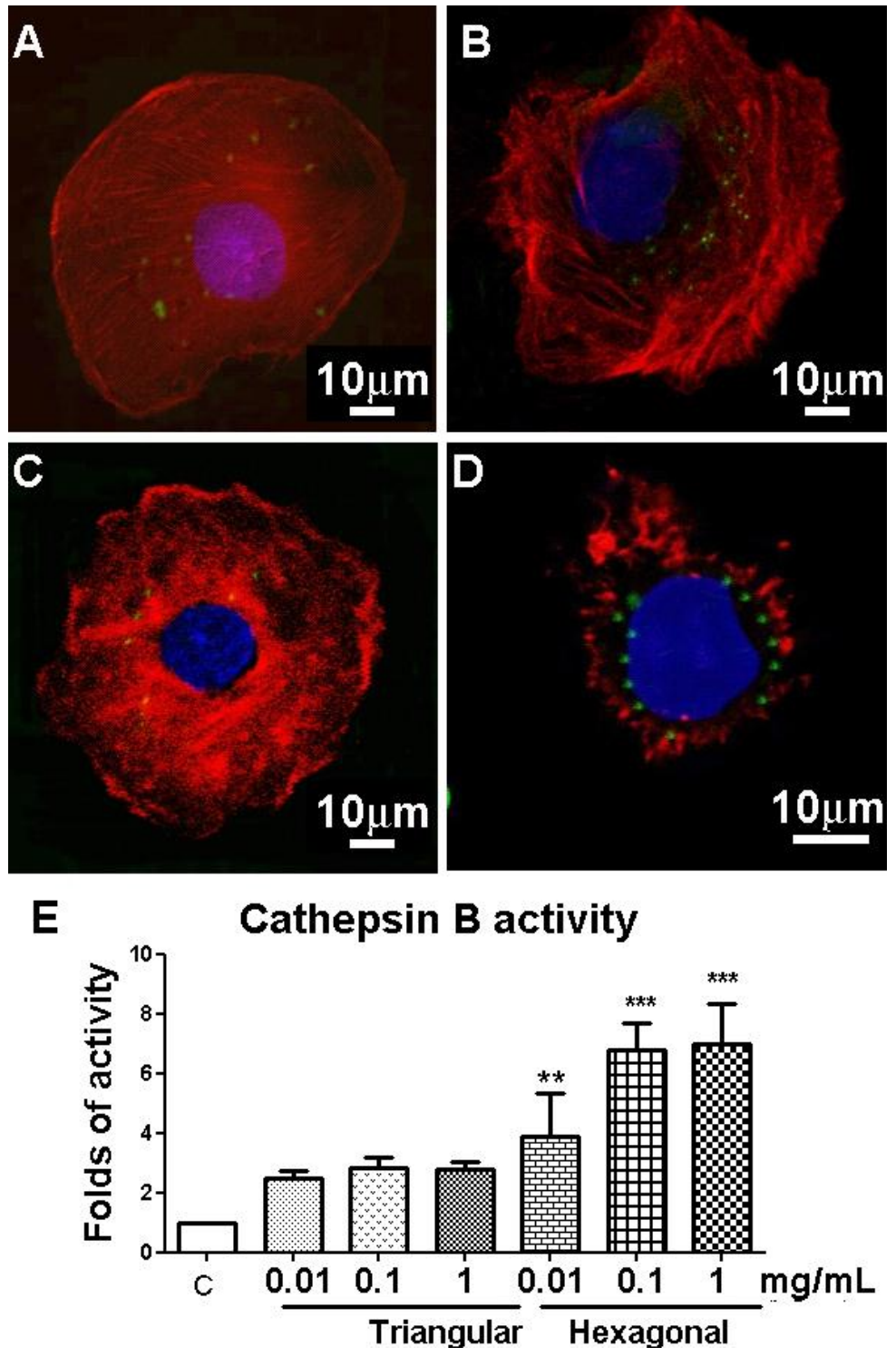

Figure 4. Cathepsin-B expression in Calu-3 epithelial cells. Laser scanning microscopy images show Calu-3 cells treated with (A) cell culture medium only, (B) spherical GNPs, (C) triangular GNPs and (D) hexagonal GNPs at $[0.2 \mathrm{mg} / \mathrm{mL}]$ for 72 hours under suspension culture conditions $\left(37^{\circ} \mathrm{C}, 5 \% \mathrm{CO}_{2}\right)$. The observed punctuated Cathepsin-B expression (green) evident in $\mathbf{D}$ indicates lysosomal localization. Limited expression is seen in both $\mathbf{B}$ and $\mathbf{C}$, although not different to that noted in $\mathbf{A}$, the negative control (cell culture medium only). The F-actin of the cell cytoskeleton (Texas Red® Phalloidin; red) and nuclei (DAPI stain; blue) were labelled to provide an indication of cell structure and status. The actin-cytoskeleton was noted to be significantly deformed following hexagonal GNP exposure compared to both spherical and triangular GNPs. (E) represents a quantified increase in Cathepsin-B activity in Calu-3 cells exposed for 72 hours to triangular and hexagonal GNPs at concentrations ranging from [0.01-1 $\mathrm{mg} / \mathrm{mL}]$.Activity levels are shown as fold changes relative to the control. Scale bars represent $10 \mu \mathrm{m}$. Images are representative of three independent experiments. 

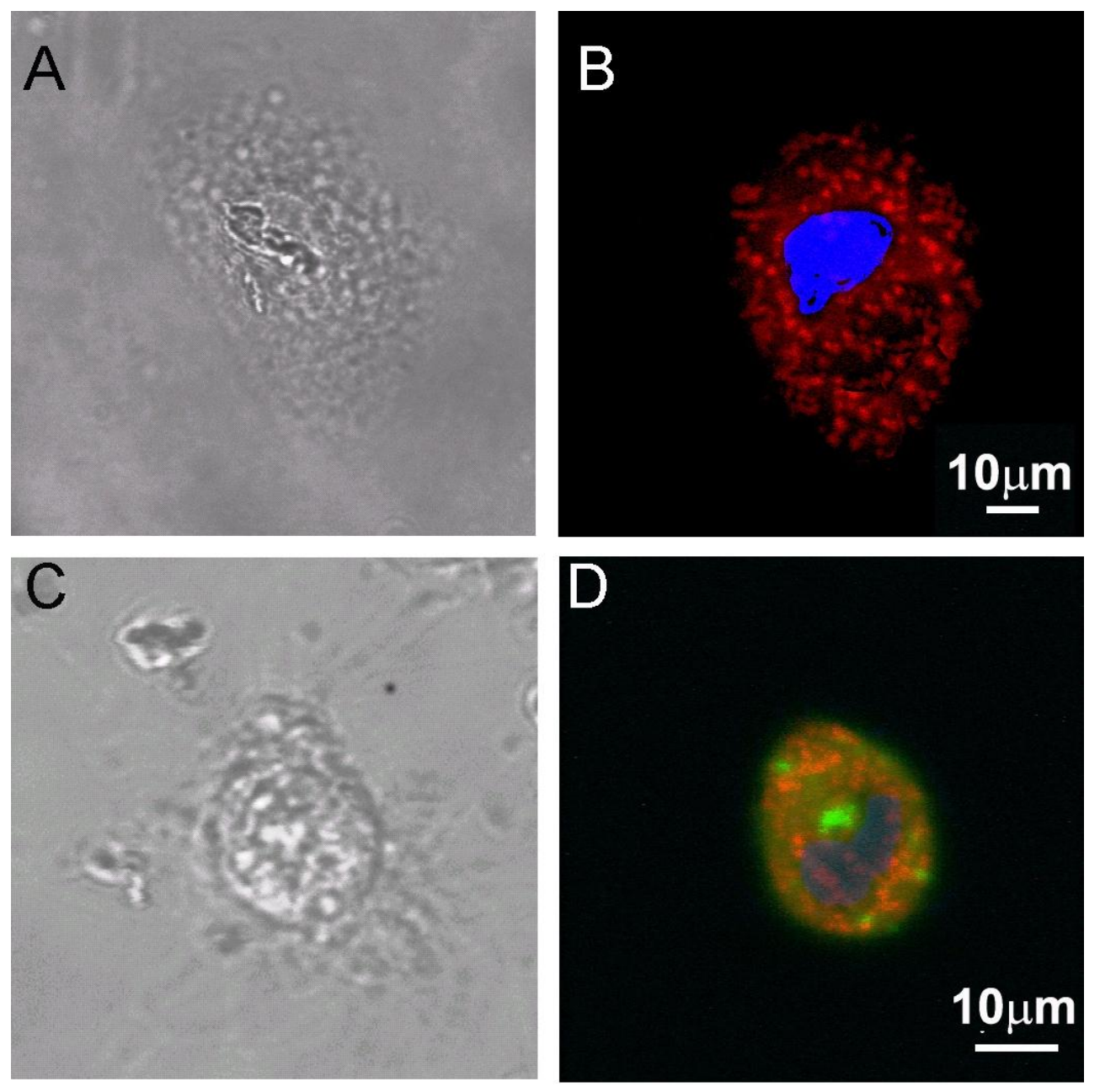

Figure 5. Reactive oxygen species (ROS) formation in Calu-3 epithelial cells. ROS formation (green) was assessed by the DCFH-DA assay and analysed for its association with the active mitochondria of the Calu-3 cells by using the fluorescent organelle marker 'Mitotracker' (red). Calu-3 cells were exposure for 72 hours to triangular (A, B) and hexagonal (C, D) GNPs at $[0.2 \mathrm{mg} / \mathrm{mL}]$ under suspension culture conditions $\left(37^{\circ} \mathrm{C}, 5 \% \mathrm{CO}_{2}\right)$. Cell nuclei (DAPI stain; blue) were also labelled to provide an indication of the structure and status of the cell. All images show merged channels for ROS formation and cellular mitochondria. Laser scanning microscopy images indicate that triangular GNPs caused limited ROS production under the experimental conditions tested. However, the hexagonal GNPs elicited an abundant increase in ROS formation over 72 hours at $[0.2 \mathrm{mg} / \mathrm{mL}]$, although this was not found to be associated within the mitochondria. Following both GNPs exposures, the no changes were evident towards the mitochondria of the Calu-3 cells. Scale bars represent $10 \mu \mathrm{m}$. Images are representative of three independent experiments. 

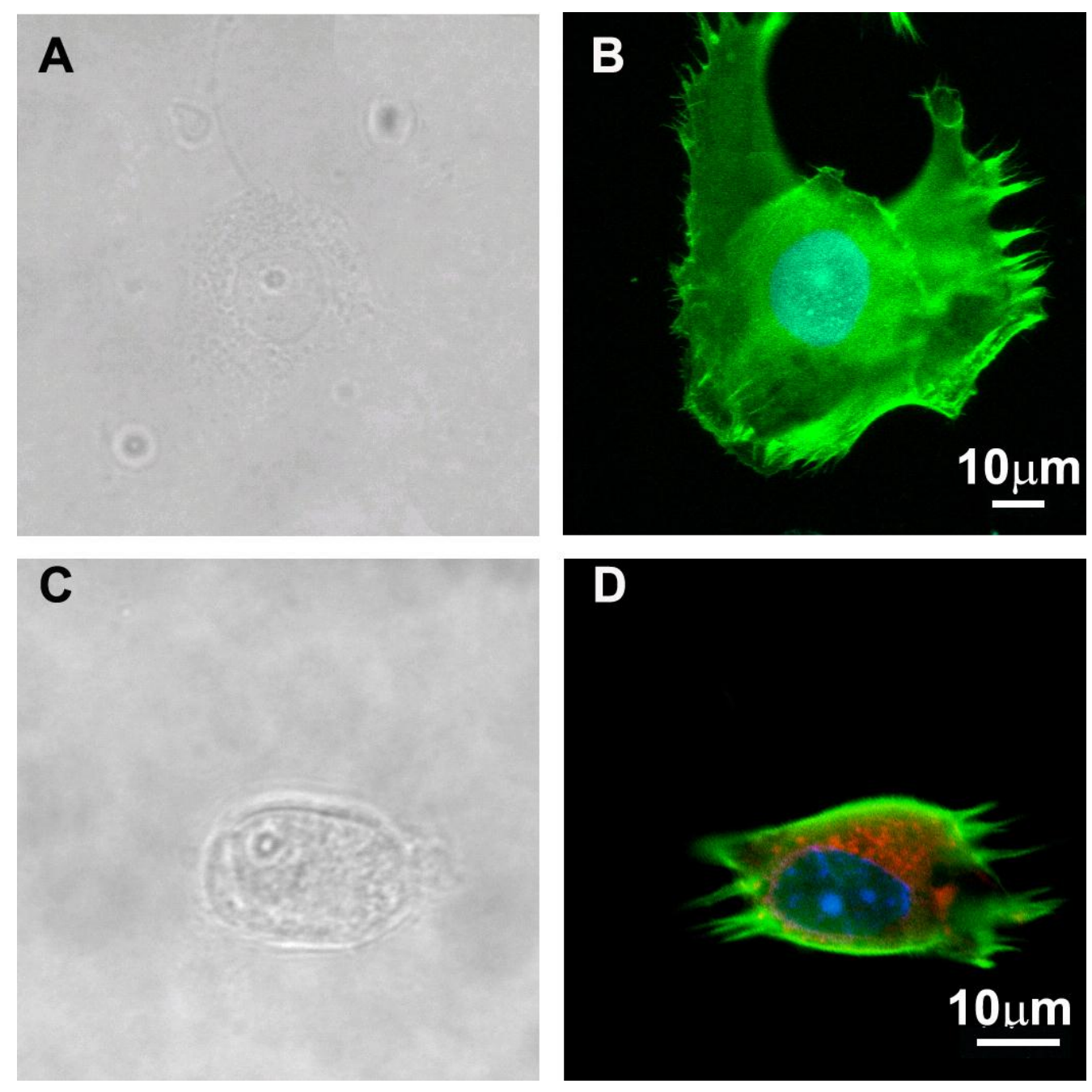

Figure 6. Caspase- 8 expression in Calu-3 epithelial cells. Laser scanning microscopy images show Calu-3 cells treated with $(\mathbf{A}, \mathbf{B})$ triangular GNPs and $(\mathbf{C}, \mathbf{D})$ hexagonal GNPs for 72 hours at $[0.2 \mathrm{mg} / \mathrm{ml}]$ under suspension culture conditions $\left(37^{\circ} \mathrm{C}, 5 \%\right.$ $\mathrm{CO}_{2}$ ). Images (B) and (D) show merged images of Caspase-8 (red) and F-actin (Phalloidin; green) staining, with the cell nuclei in blue (DAPI; blue). After treatment with hexagonal GNPs the integrity of the cytoskeleton of the Calu-3 cells was found to alter compared to treatment with triangular GNPs. Following treatment with hexagonal GNPs however, a clear increase in Caspase-8 production was noted compared to the epithelial cells treated with triangular GNPs. Scale bars represent 10 $\mu \mathrm{m}$. Images are representative of three independent experiments. 
A

Fas GNPS I

Caspase-3

Caspase- 9

$\beta$-actin

Spherical

Triangular Hexagonal
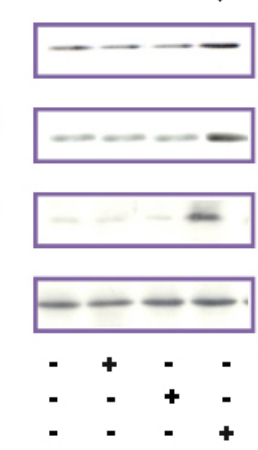

B
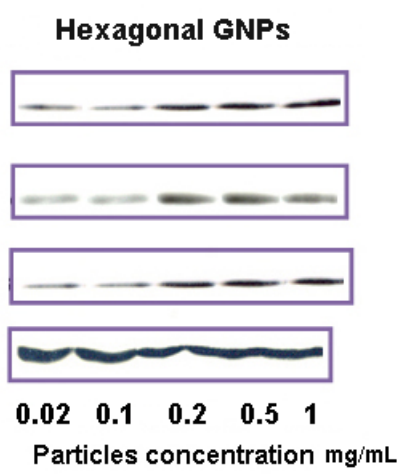

C

Fas

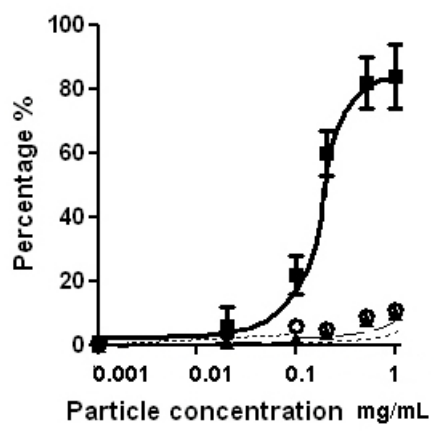

D

D

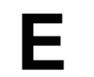

Caspase 3

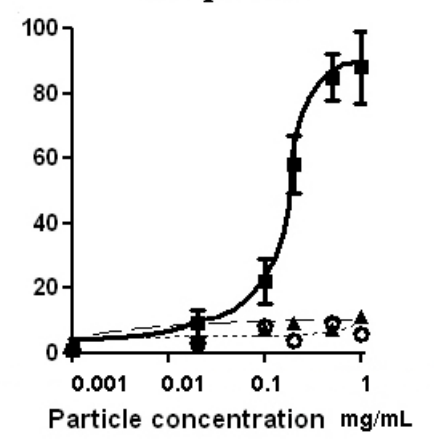

Caspase 9

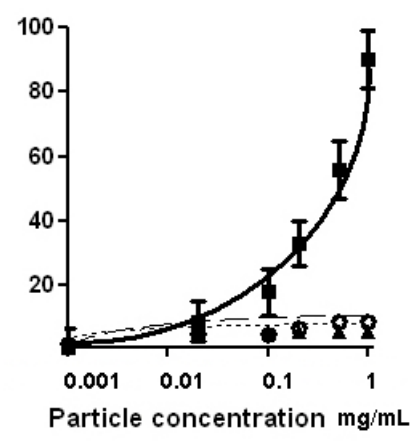

Figure 7. Shape-dependent expression of apoptosis-related proteins (Fas, Caspase-3 and Caspase-9) in Calu-3 epithelial cells after treatment to alternative shaped GNPs for 72 hours under suspension culture conditions $\left(37^{\circ} \mathrm{C}, 5 \% \mathrm{CO}_{2}\right)$. (A) arrow points last column of Western blot anlaysis for Fas ( 50 kDa), Caspase-3 (cleaved 19kDa form) and Caspase-9 (cleaved $21 \mathrm{kDa}$ form) showing different protein expressions after Calu-3 cells were exposed to [1 mg/mL] of spherical, triangular or hexagonal shaped GNPs. (B) shows different protein expression in cells exposed to hexagonal GNPs at $[0.02,0.1,0.2,0.5$ and $1 \mathrm{mg} / \mathrm{mL}]$. Graphs C-E show the relative percentages of Fas death receptor, effector Caspase-3 and initiator Caspase-9 following Calu-3 cell treatment with $[1 \mathrm{mg} / \mathrm{ml}]$ GNPs ( $\boldsymbol{\sim}$ hexagonal shaped GNPs, $\boldsymbol{\Delta}$ triangular shaped GNPs, o spherical shaped GNPs) ( $\mathrm{n}=3)$. 
Table 1. Key physicochemical characteristics of the different shaped GNPs used.

\begin{tabular}{|c|c|c|c|c|c|c|c|}
\hline Sample & $\begin{array}{l}\text { Diameter } \\
\text { (nm) }\end{array}$ & $\begin{array}{c}\text { Thickness } \\
\text { (nm) }\end{array}$ & $\begin{array}{c}\text { Surface } \\
\text { Area per } \\
\text { GNP }\left(\mathbf{n m}^{2}\right)\end{array}$ & $\begin{array}{c}\text { Volume } \\
\text { per } \\
\text { GNP } \\
\left(\mathbf{n m}^{3}\right)\end{array}$ & $\begin{array}{c}\text { Surface } \\
\text { modification }\end{array}$ & $\begin{array}{l}\lambda_{\max } \\
(\mathbf{n m})\end{array}$ & $\begin{array}{c}\text { Zeta } \\
\text { potential } \\
\text { in cell } \\
\text { culture } \\
\text { medium } \\
(\mathrm{mV}) \\
\end{array}$ \\
\hline Spherical & 30 & - & 2827.4 & 14137 & $\begin{array}{c}\text { HS-PEG- } \\
\text { COOH }\end{array}$ & 528 & $\begin{array}{c}- \\
17.3 \pm 1.2\end{array}$ \\
\hline Triangular & 120 & 9 & 12470.4 & 56118 & $\begin{array}{c}\text { HS-PEG- } \\
\mathrm{COOH}\end{array}$ & 900 & $\begin{array}{c}- \\
17.7 \pm 1.9\end{array}$ \\
\hline Hexagonal & 150 & 9 & 38971.1 & 131528 & $\begin{array}{c}\text { HS-PEG- } \\
\mathrm{COOH}\end{array}$ & 1100 & $\begin{array}{c}- \\
16.3 \pm 1.1\end{array}$ \\
\hline
\end{tabular}

Table 2. Quantification of cell associated GNPs as calculated by Atomic Absorption Spectroscopy (AAS) in Calu-3 cells after 72 hours exposure at $1 \mathrm{mg} / \mathrm{mL}$.

\begin{tabular}{|c|c|c|c|c|c|c|c|}
\hline $\begin{array}{l}\text { GNP } \\
\text { Shape }\end{array}$ & $\begin{array}{l}\text { Total Au mass } \\
\text { per dish (mg) }\end{array}$ & $\begin{array}{c}\text { Total Au } \\
\text { volume per } \\
\text { dish }\left(\mathbf{m}^{3}\right)\end{array}$ & $\begin{array}{c}\text { GNP } \\
\text { volume }\left(\mathbf{m}^{3}\right)\end{array}$ & $\begin{array}{l}\text { GNPs per } \\
\text { dish }\end{array}$ & $\begin{array}{c}\text { Cells } \\
\text { per } \\
\operatorname{dish} \dagger\end{array}$ & $\begin{array}{c}\text { Estimated } \\
\text { GNPs per } \\
\text { cell }\end{array}$ & $\begin{array}{c}\text { GNP } \\
\text { mass } \\
\text { per } \\
\text { cell } \\
\text { (ng) }\end{array}$ \\
\hline Sphere & $0.11 \pm 0.04$ & $\begin{array}{c}5.69 \pm 2.07 \\
\times 10^{-12}\end{array}$ & $\begin{array}{c}1.41 \pm 0.51 \\
\times 10^{-23}\end{array}$ & $\begin{array}{c}4.03 \pm 1.47 \\
\times 10^{11}\end{array}$ & $\begin{array}{c}5 \pm 1.82 \\
\times 10^{5}\end{array}$ & $\begin{array}{c}8.06 \pm 2.93 \\
\times 10^{5}\end{array}$ & 0.22 \\
\hline Triangle & $0.19 \pm 0.08$ & $\begin{array}{c}9.84 \pm 4.14 \\
\times 10^{-12}\end{array}$ & $\begin{array}{c}6.24 \pm 2.62 \\
\times 10^{-23}\end{array}$ & $\begin{array}{c}1.58 \pm 0.66 \\
\times 10^{11}\end{array}$ & $\begin{array}{c}4.5 \pm 1.9 \\
\times 10^{5}\end{array}$ & $\begin{array}{c}3.51 \pm 1.47 \\
\times 10^{5}\end{array}$ & 0.42 \\
\hline Hexagon & $0.53 \pm 0.05^{*}$ & $\begin{array}{c}2.74 \pm 0.26 \\
\times 10^{-11}\end{array}$ & $\begin{array}{c}1.46 \pm 0.13 \\
\times 10^{-22}\end{array}$ & $\begin{array}{c}1.88 \pm 1.77 \\
\times 10^{11}\end{array}$ & $\begin{array}{c}2 \pm 0.19 \\
X 10^{5}\end{array}$ & $\begin{array}{c}9.40 \pm 0.89 \\
\times 10^{5}\end{array}$ & 2.65 \\
\hline
\end{tabular}

${ }^{*} p<0.01 ;$ Au density $=1.93 \mathrm{E}+07 \mathrm{~g} / \mathrm{m}^{3}$

$\uparrow$ The different cell number per dish reported is related to the cytotoxicity observed following Calu-3 exposures. 


\section{REFERENCES}

1. Sanz V, Conde J, Hernández Y, Baptista PV, Ibarra MR, de la Fuente JM. Effect of PEG biofunctional spacers and TAT peptide on dsRNA loading on gold nanoparticles. . J Nanoparticles Res, 14, 917 (2012).

2. Bhaskar S, Tian F, Stoeger $\mathrm{T}$ et al. Multifunctional Nanocarriers for diagnostics, drug delivery and targeted treatment across blood-brain barrier: perspectives on tracking and neuroimaging. Part Fibre Toxicol, 7, 3 (2010).

3. Brandenberger C, Clift MJ, Vanhecke D et al. Intracellular imaging of nanoparticles: is it an elemental mistake to believe what you see? Part Fibre Toxicol, 7(15), 1-6 (2010).

4. Conde J, Bao C, Cui D, Baptista PV, Tian F. Antibody-drug gold nanoantennas with Raman spectroscopic fingerprints for in vivo tumour theranostics. J Control Release, 183, 87-93 (2014).

5. Gratton SE, Ropp PA, Pohlhaus PD et al. The effect of particle design on cellular internalization pathways. Proc Natl Acad Sci U S A, 105(33), 1161311618 (2008).

6. Hutter E, Boridy S, Labrecque $\mathrm{S}$ et al. Microglial response to gold nanoparticles. ACS Nano, 4(5), 2595-2606 (2010).

7. Pelaz B, Charron G, Pfeiffer C et al. Interfacing engineered nanoparticles with biological systems: anticipating adverse nano-bio interactions. Small, 9(9-10), 1573-1584 (2013).

8. Bao C, Beziere N, Del Pino P et al. Gold nanoprisms as optoacoustic signal nanoamplifiers for in vivo bioimaging of gastrointestinal cancers. Small, 9(1), 68-74 (2013).

9. Conde J, Tian F, Hernandez Y et al. In vivo tumor targeting via nanoparticlemediated therapeutic siRNA coupled to inflammatory response in lung cancer mouse models. Biomaterials, 34(31), 7744-7753 (2013).

10. Kinnear C, Dietsch H, Clift MJ, Endes C, Rothen-Rutishauser B, Petri-Fink A. Gold nanorods: controlling their surface chemistry and complete detoxification by a two-step place exchange. Angew Chem Int Ed Engl, 52(7), 1934-1938 (2013).

11. Nehl CL, Hafner JH. Shape-dependent plasmon resonances of gold nanoparticles. Journal of Materials Chemistry, 18(21), 2415-2419 (2008).

12. Uboldi $\mathrm{C}$, Bonacchi D, Lorenzi G et al. Gold nanoparticles induce cytotoxicity in the alveolar type-II cell lines A549 and NCIH441. Part Fibre Toxicol, 6, 18 (2009).

13. Pelaz B, Grazu V, Ibarra A, Magen C, del Pino P, de la Fuente JM. Tailoring the synthesis and heating ability of gold nanoprisms for bioapplications. Langmuir, 28(24), 8965-8970 (2012).

14. Orendorff CJ, Sau TK, Murphy CJ. Shape-dependent plasmon-resonant gold nanoparticles. Small, 2(5), 636-639 (2006).

15. Ambrosone A, Pino PD, Marchesano V, Parak WJ, de la Fuente JM, Tortiglione C. Gold nanoprisms for photothermal cell ablation in vivo. Nanomedicine (Lond), 1-10 (2014).

16. Ankamwar B, Chaudhary M, Sastry M. Gold Nanotriangles Biologically Synthesized using Tamarind Leaf Extract and Potential Application in Vapor Sensing. Synthesis and Reactivity in Inorganic, Metal-Organic, and NanoMetal Chemistry, 35(1), 19 - 26 (2005). 
17. Chithrani BD, Ghazani AA, Chan WC. Determining the size and shape dependence of gold nanoparticle uptake into mammalian cells. Nano Lett, 6(4), 662-668 (2006).

18. Unfried K, Albrecht C, Klotz L-O, Mikecz AV, Grether-Beck S, Schins RPF. Cellular responses to nanoparticles: Target structures and mechanisms. Nanotoxicology, 1, 52-71 (2007).

19. Agarwal R, Singh V, Jurney P, Shi L, Sreenivasan SV, Roy K. Mammalian cells preferentially internalize hydrogel nanodiscs over nanorods and use shape-specific uptake mechanisms. Proc Natl Acad Sci U S A, 110(43), 1724717252 (2013).

20. Liu Y, Tan J, Thomas A, Ou-Yang D, Muzykantov VR. The shape of things to come: importance of design in nanotechnology for drug delivery. Ther Deliv, 3(2), 181-194 (2012).

21. Bartneck M, Keul HA, Singh S et al. Rapid uptake of gold nanorods by primary human blood phagocytes and immunomodulatory effects of surface chemistry. ACS Nano, 4(6), 3073-3086 (2010).

22. Qiu Y, Liu Y, Wang L et al. Surface chemistry and aspect ratio mediated cellular uptake of Au nanorods. Biomaterials, 31(30), 7606-7619 (2010).

23. Conde J, Ambrosone A, Sanz V et al. Design of multifunctional gold nanoparticles for in vitro and in vivo gene silencing. ACS Nano, 6(9), 83168324 (2012).

24. Borm PJ, Kreyling W. Toxicological hazards of inhaled nanoparticles-potential implications for drug delivery. J Nanosci Nanotechnol, 4(5), 521-531 (2004).

25. Rivera-Gil P, Jimenez de Aberasturi D, Wulf $\mathrm{V}$ et al. The challenge to relate the physicochemical properties of colloidal nanoparticles to their cytotoxicity. Acc Chem Res, 46(3), 743-749 (2013).

26. Jokerst JV, Lobovkina T, Zare RN, Gambhir SS. Nanoparticle PEGylation for imaging and therapy. Nanomedicine (Lond), 6(4), 715-728 (2011).

27. Tkachenko A, Xie H, Franzen S, Feldheim DL. Assembly and characterization of biomolecule-gold nanoparticle conjugates and their use in intracellular imaging. Methods Mol Biol, 303, 85-99 (2005).

28. Mukherjee SG, O'Claonadh N, Casey A, Chambers G. Comparative in vitro cytotoxicity study of silver nanoparticle on two mammalian cell lines. Toxicology in vitro : an international journal published in association with BIBRA, 26(2), 238-251 (2012).

29. Bouwmeester H, Lynch I, Marvin HJ et al. Minimal analytical characterization of engineered nanomaterials needed for hazard assessment in biological matrices. Nanotoxicology, 5(1), 1-11 (2011).

30. Vanhecke D, Rodriguez-Lorenzo L, Clift MJD, Blank F, Petri-Fink A, Rothen-Rutishauser B. Quantification of the nanoparticle-cell interaction - an overview about the state-of-the-art techniques and their limitations. . Nanomedicine (London), in Press (2014).

31. Herzog E, Casey A, Lyng FM, Chambers G, Byrne HJ, Davoren M. A new approach to the toxicity testing of carbon-based nanomaterials--the clonogenic assay. Toxicol Lett, 174(1-3), 49-60 (2007).

32. Tian F, Prina-Mello A, Estrada G et al. A novel assay for the quantification of internalized nanoparticles in macrophages. Nanotoxicology, 2(4), 232 - 242 (2008). 
33. Tian F, Nakahara T, Yoshida M, Honda N, Hirose H, Miyakoshi J. Exposure to power frequency magnetic fields suppresses $\mathrm{X}$-ray-induced apoptosis transiently in Ku80-deficient xrs5 cells. Biochem Biophys Res Commun, 292(2), 355-361 (2002).

34. Clift MJ, Brandenberger C, Rothen-Rutishauser B, Brown DM, Stone V. The uptake and intracellular fate of a series of different surface coated quantum dots in vitro. Toxicology, 286(1-3), 58-68 (2011).

35. Clift MJ, Rothen-Rutishauser B, Brown DM et al. The impact of different nanoparticle surface chemistry and size on uptake and toxicity in a murine macrophage cell line. Toxicol Appl Pharmacol, 232(3), 418-427 (2008).

36. Clift MJ, Varet J, Hankin SM et al. Quantum dot cytotoxicity in vitro: an investigation into the cytotoxic effects of a series of different surface chemistries and their core/shell materials. Nanotoxicology, 5(4), 664-674 (2011).

37. Oberdorster G. Safety assessment for nanotechnology and nanomedicine: concepts of nanotoxicology. J Intern Med, 267(1), 89-105 (2010).

38. Brandenberger C, Rothen-Rutishauser B, Muhlfeld C et al. Effects and uptake of gold nanoparticles deposited at the air-liquid interface of a human epithelial airway model. Toxicol Appl Pharmacol, 242(1), 56-65 (2010).

39. Li N, Zhao P, Astruc D. Anisotropic gold nanoparticles: synthesis, properties, applications, and toxicity. Angew Chem Int Ed Engl, 53(7), 1756-1789 (2014).

40. Zeng Q, Shaob D, Ji W, Li J, Chen L, Song J. The nanotoxicity investigation of optical nanoparticles to cultured cells in vitro. Toxicology Reports, 1, 137144 (2014).

41. Stoeger T, Reinhard C, Takenaka S et al. Instillation of six different ultrafine carbon particles indicates a surface area threshold dose for acute lung inflammation in mice. Environ Health Perspect, 114(3), 328-333 (2006).

42. Tian F, Cui D, Schwarz H, Estrada GG, Kobayashi H. Cytotoxicity of singlewall carbon nanotubes on human fibroblasts. Toxicol In Vitro, 20(7), 12021212 (2006).

43. Ferin J, Oberdorster G, Penney DP. Pulmonary retention of ultrafine and fine particles in rats. Am J Respir Cell Mol Biol, 6(5), 535-542 (1992).

44. Duffin R, Tran C, A. C et al. The importance of surface area and specific reactivity in the acute pulmonary inflammatory response to particles. . Ann Occ Hyg 46(242-245) (2002).

45. Duffin R, Tran L, Brown D, Stone V, Donaldson K. Proinflammogenic effects of low-toxicity and metal nanoparticles in vivo and in vitro: highlighting the role of particle surface area and surface reactivity. Inhal Toxicol, 19(10), 849856 (2007).

46. Nativo P, Prior IA, Brust M. Uptake and intracellular fate of surface-modified gold nanoparticles. ACS Nano, 2(8), 1639-1644 (2008).

47. Buzea C, Pacheco, II, Robbie K. Nanomaterials and nanoparticles: sources and toxicity. Biointerphases, 2(4), MR17-71 (2007).

48. Neilson JH, Gilchrist A. Erosion by stream of solid particles. Wear, 11, 111 (1968).

49. Hinderliter PM, Minard KR, Orr G et al. ISDD: A computational model of particle sedimentation, diffusion and target cell dosimetry for in vitro toxicity studies. Part Fibre Toxicol, 7(1), 36 (2010). 
50. Cohen JM, Teeguarden JG, Demokritou P. An integrated approach for the in vitro dosimetry of engineered nanomaterials. Part Fibre Toxicol, 11, 20 (2014). 